\title{
Behaviour of Surface Defects in Wire Rod Rolling
}

\author{
Mirjana Filipović 1), Conny Eriksson 2), Henrik Överstam ${ }^{3)}$ \\ 1) National Post Gradual School in Metal Forming, Dalarna University, SE-781 88 Borlänge, Sweden. \\ 2) Fagersta Stainless AB, Box 508, SE-737 25 Fagersta, Sweden. \\ 3) Mechanical Engineering, Department of Technology, Örebro University, SE-701 82 Örebro, Sweden.
}

Defects are often present in rolled products, such as wire rod. The market demand for wire rod without any defects has increased. In the final wire rod products, defects originating from steel making, casting, pre-rolling of billets and during wire rod rolling can appear. In this work, artificial $V$-shaped longitudinal surface cracks have been analysed experimentally and by means of FEM. The results indicate that the experiments and FEM calculations show the same tendency except in two cases, where instability due to fairly "round" false round bars disturbed the experiment. FE studies in combination with practical experiments are necessary in order to understand the behaviour of the material flows in the groove and to explain whether the crack will open up as a V-shape or if it will be closed as an l-shape.

Keywords: artificial surface cracks, wire rod, working range, roll pass design, FE-analysis

\section{Introduction}

In bar and wire rod rolling, steel is heated above its temperature of recrystallization and passed through several grooves in the rolling mill. Typical series of grooves are diamond-diamond, diamond-square and box passes upstream in the roughing mill and square-oval or false round-oval downstream in the rolling line. The target is to obtain high productivity by high finish rolling speed, and to reduce the downtime in production caused by maintenance stops, adjustments, and lag due to waiting for the right heating temperature between different steel grades. With modern technologies, including the wire rod block, the finish rolling speed for rolling $5.5 \mathrm{~mm}$ wire rod has increased up to 100 $140 \mathrm{~m} / \mathrm{s}[1,2]$. It is possible to roll all types of steel, even stainless steels such as austenitic, ferritic, duplex and martensitic types and nickel based alloys, but the rolling speed is limited due to adiabatic heating of the material. Different steel grades require different heating and rolling temperatures.

Market demands for high quality wire rod increased dramatically in the later $20^{\text {th }}$ century. For most applications no defects in the wire rod are accepted. Wire rod producers are therefore constantly looking for better methods to assure the quality of their products.

The aim of this work is to study if it would be possible to eliminate the cracks or minimise their negative influence in bar and wire rod rolling by improving the roll pass series.

\section{Surface Cracks in Wire Rod Rolling}

There are many sources for defect formation [3]. To decide how serious the defect is, it is important to exactly monitor and measure the position, shape and depth of the cracks.

During ingot casting, defects will be formed if the molten metal is not poured carefully at the correct temperature. In continuous casting it was observed that the primary reason for corner cracks is non-uniform cooling conditions, which can lead to stress concentration in that part of the material [4]. Localized impurities in billets, shrinkage cavities and segregation give cracks in the billets. In order to improve the surface quality of the final products, it is often necessary to grind the billets before rolling. Defects caused by overfilled grooves, called laps or fins, can be a result of too large reductions or improper roll adjustment. Surface cracks, caused by low ductility during rolling are common in rolling stainless steels and high-speed steel. For ferritic stainless steels, surface cracks are common.

The topology of surface cracks are often changes during the rolling process and appear mostly inclined in relation to the normal direction on the surface. A typical crack after the rolling process is shown in Figure 1.

Roll pass design. Common roll pass designs used in bar and wire rod mills are diamond-square, diamond-diamond, box passes, square-oval, false round-oval, and round-oval. The characteristics of the square-oval and false round-oval sequences are shown in Figure 2. In the figure, the bar and the groove geometries are defined. The fitting factor is defined by the ratio of the oval edge height $(O E)$ and the bottom diameter $(D S)$ of the square groove.

A good pass design must guarantee stable rolling. The target for roll pass designers is to ensure the production of the desired shape of a product with the appropriate structure,

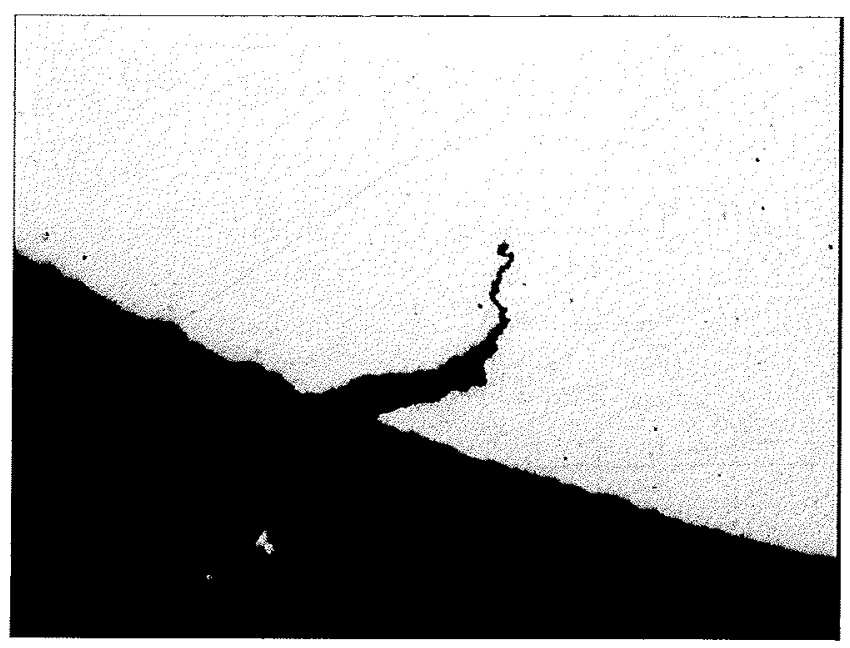

Figure 1. Typical crack in wire rod. 
good surface without any defects and at the lowest possible cost.

The square-oval series are stable and have a relatively high reduction capacity. The squares are twisted $45^{\circ}$ before entering the following oval. After reduction, the ovals are turned $90^{\circ}$ before entering the following square. This series is not recommended for rolling of heavy sections, but it is common in intermediate rolling lines. Roller guides are normally used to stabilise the oval bars before entering the square grooves.

False round-oval series are very popular in continuous mills. The reduction capacity is usually about $17 \%$ per pass, but can be considerably higher when using flat ovals [5]. When rolling in horizontal stands only, the bar is turned $90^{\circ}$ before entering the following groove, but usually every second stand is placed in a vertical position and no twisting of the bar is necessary. Roller guides are needed to stabilise the oval bar entering the false round grooves. A special sequence is round-oval, which compared to false round-oval gives lower flexibility. This pass design is commonly used in wire rod blocks.

Diamond-square, or diamond-diamond, have lower reduction capacity than the square-oval series. The series are stable and commonly used in roughing mills [6].

State of the art. Many studies of the behaviour of surface defects in rolling have been carried out [7-12]. Wallner [7] analysed the behaviour of artificial cracks related to the fitting factor $(O E / D S)$. From the results it was concluded that the cracks decreased for fitting factors of $0.28-0.30$. He also found that the crack depth was reduced slowly for fitting factors larger than 0.71 compared to the lower fitting factors, where the crack depths decreased rapidly. His general conclusions were that the false round-oval series has better capability for reducing all cracks at all positions compared to square-oval. A fitting factor below 0.25 is not recommended because of high wear in the square groove bottom.

Matsui et al. [9] studied a diamond-square and squareoval pass design to roll billets with artificial cracks. They found that defects in the groove bottom and on the free side strongly decreased. In square-oval sequences, the cracks decreased in contact with the groove, but cracks on the free side were closed and increased in depth. The most efficient method for eliminating a crack is if the material flows up in the radial direction and opens up in the angular direction when the material elongates.

Lim et al. [10] showed that improper groove design, lower rolling temperature and the scale conditions of the billets are the main factors for causing wrinkles. They concluded that the depth of the wrinkles could be improved by changing from box and box-oval to oval grooves in order to get convex edges instead of concave.

Ervasti and Ståhlberg [11] studied the behaviour of a longitudinal V-shaped crack, on the surface of a continuous cast steel slab during hot rolling. The results indicate that the reduction of the crack followed the material reduction at the beginning of the rolling, but was less reduced at the end of the rolling series.

Eriksson [12] studied the behaviour of artificial cracks when rolling false round-oval series. He defined an equivalent crack depth related to the initial crack depth shown in Eq. (1). He proposed that the depth of a crack should be compared to the cross-sectional area of the bar. For example, if a crack of $1 \mathrm{~mm}\left(d_{0}\right)$ depth on a round bar of $25 \mathrm{~mm}$ changes to a depth of $0.4 \mathrm{~mm}\left(d_{i}\right)$ after rolling to a round $10 \mathrm{~mm}$ bar, the relative crack depth is the same as shown by Eq. (2). If the "relative crack depth" $\left(c_{i}^{\text {rel }}\right)$, calculated by Eq. $(2)$, is plotted versus the pass number, a positive inclination indicates that the "relative crack depth" increases. On the other hand, by negative inclination the crack is reduced.
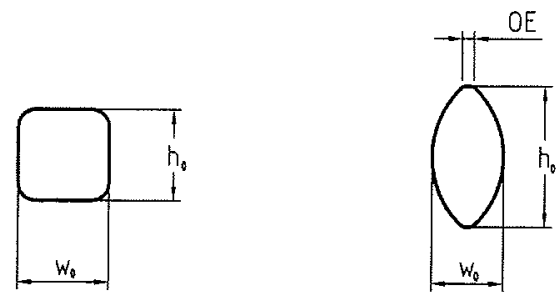

$\Downarrow$

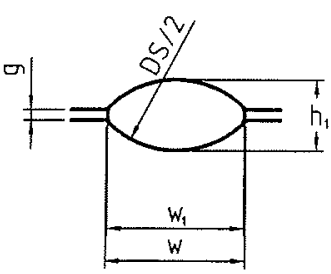

(a)

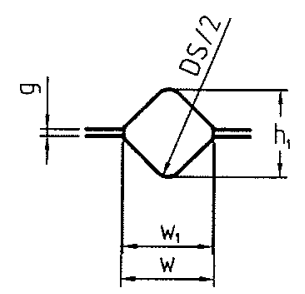

(b)

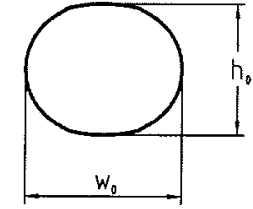

$\Downarrow$

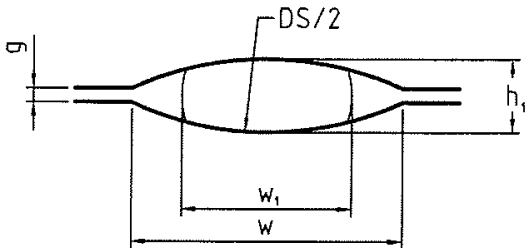

(c)

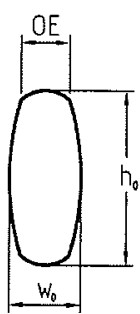

$\downarrow$

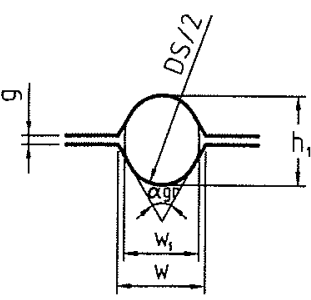

(d)

Figure 2. Common sequences in roll in wire rod rolling. (a) square-oval, (b) oval-square, (c) round-oval, (d) oval-round. 

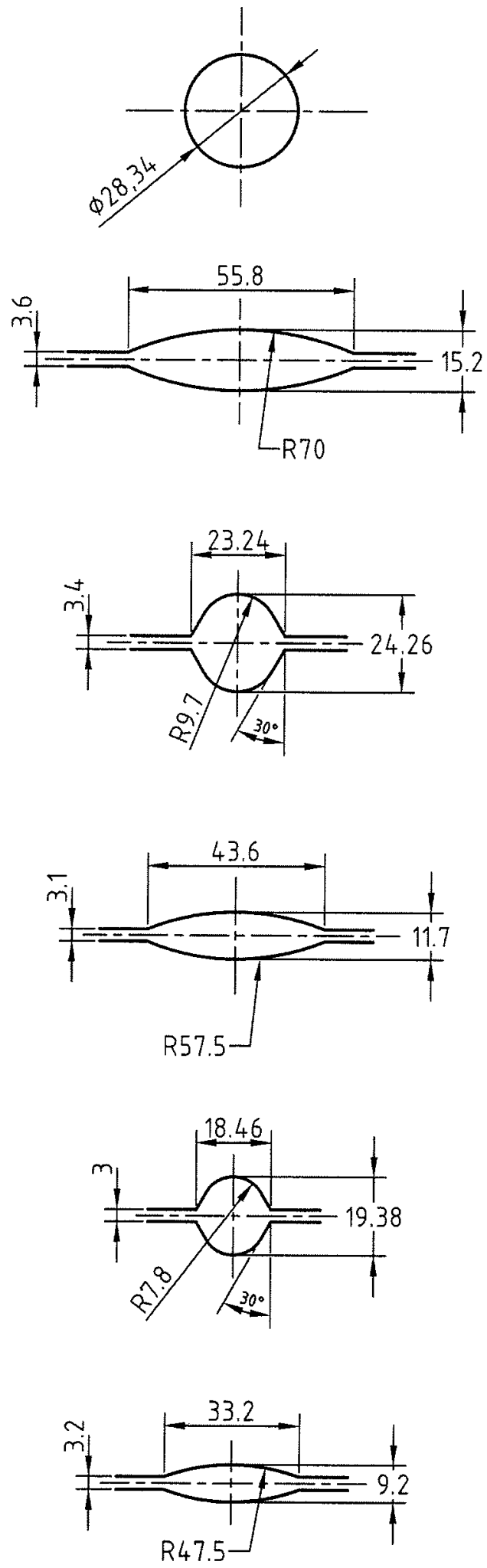

(a)

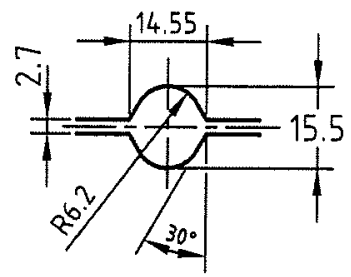

$$
\begin{aligned}
& c_{i}=\frac{d_{i}}{d_{0}} \\
& c_{i}^{r e l}=c_{i} \sqrt{\lambda_{i}}=c_{i} \sqrt{\frac{l_{i}}{l_{0}}}=c_{i} \sqrt{\frac{A_{0}}{A_{i}}} \\
& 1 \leq i \leq n
\end{aligned}
$$

\section{Analysis of Crack Development in False Round-Oval Sequences}

Experiments. Laboratory experiments were carried out at the Royal Institute of Technology (KTH). Round highspeed steel bars SS 2722 (AISI/SAE M2) of $28.34 \mathrm{~mm}$ were rolled in false round-oval series of six passes with $23 \%$ average reduction, shown in Figure 3a. The roll diameter was $320 \mathrm{~mm}$. Three artificial V-shaped cracks with $1.7 \mathrm{~mm}$ depth and $0.5 \mathrm{~mm}$ opening were prepared on nine bars at positions shown in Figure $\mathbf{3 b}$. On each of the bars the cracks were oriented at $0^{\circ}, 45^{\circ}$ and $90^{\circ}$.

The bars were heated in an electrical laboratory furnace up to $1100 \pm 5^{\circ} \mathrm{C}$ in $10-20 \mathrm{~min}$, depending on dimension. The furnace was percolated with nitrogen to prevent formation of oxide scale. The rolling speed was around $3.1-3.2 \mathrm{~m} / \mathrm{s}$. For every pass, samples were taken in order to investigate the behaviour of the cracks.

Numerical study of the local strains around the surface defects. In a FEM-analysis the equivalent crack depth $\left(c_{i}\right)$ can be described as a direct function of the radial strain in the crack field. The equivalent crack depths $\left(c_{\varphi}\right)$ are related to the true strain by the Eq. (3).

$$
c_{\varphi}=\exp \left(\varepsilon_{\varphi r}\right)
$$

An FE package MSC.MARC was used to perform a fully 3-dimensional analysis of the crack behaviour. The wire rod was modelled with eight node isoparametric brick elements with eight integration points. The element uses trilinear interpolation functions, the strains therefore tends to be constant throughout the element which can cause poor

Entry bar

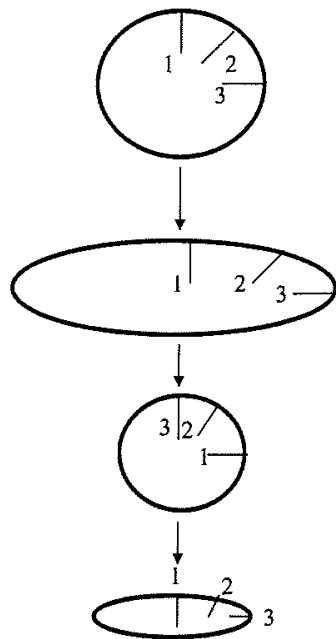

Figure 3. (a) Roll pass design in experiments, (b) position of V-shaped cracks denoted $\{1\},\{2\}$ and $\{3\}$ in the experiments. 


\begin{tabular}{|l|l|l|}
\hline \multicolumn{2}{|c|}{ Nomenclature } \\
Symbol & Unit & Explanation \\
\hline Latin letters & & \\
$A_{0}$ & $\mathrm{~mm}^{2}$ & entry bar area \\
$A_{i}$ & $\mathrm{~mm}^{2}$ & exit bar area \\
$A_{1}, A_{2}, A_{3}$ & - & constant in Hensel-Spittel model \\
$m_{1}, m_{2}, m_{3}$ & - & constant in Hensel-Spittel model \\
$n_{r}$ & $\mathrm{rad} / \mathrm{s}$ & angular velocity \\
$T$ & ${ }^{\circ} \mathrm{C}$ & temperature \\
$\varnothing$ & $\mathrm{mm}$ & round wire rod diameter \\
$D S$ & $\mathrm{~mm}$ & diameter at groove bottom \\
$c_{i}$ & - & equivalent crack depth \\
$d_{i}$ & $\mathrm{~mm}$ & crack depth \\
$l_{l}$ & $\mathrm{~mm}$ & entry bar length \\
$l_{j} l_{i}$ & $\mathrm{~mm}$ & exit bar length \\
OE & $\mathrm{mm}$ & edge height of oval \\
OE/DS & - & fitting factor \\
$m$ & - & friction factor \\
\hline Greek letters & & \\
$\lambda$ & - & elongation \\
$\sigma_{0}$ & $\mathrm{MPa}$ & constant in Hensel-Spittel model \\
$\sigma$ & $\mathrm{MPa}$ & flow stress \\
$\varepsilon$ & - & true strain \\
$\varepsilon$ & $\mathrm{s}^{-1}$ & true strain velocity \\
\hline Subscripts & & \\
$i . n$ & - & current pass number, final pass number \\
\hline Superscript & & \\
rel & - & relative \\
\hline
\end{tabular}

shear behaviour. This element is steel preferred over higher order element in contact analyses. Due to the symmetry, one quarter of the cross-section was used in order to shorten the computation time. The rolls were considered to be rigid and were therefore modelled by surface elements with constant angular velocity and constant temperature. The angular velocity $\left(n_{r}\right)$ of the rolls was constant, $20 \mathrm{rad} / \mathrm{s}$. The friction was modelled by a shear model with a shear stress factor $(m)$ of 0.6 .

The material was modelled as an elastic-plastic isotropic hardening material and von Mises yield criterion was used. The yield stress was modelled according to Hensel and Spittel [13] with the formulation in Eq. (4):

$$
\sigma=\sigma_{0} A_{1} e^{-m_{1} T} A_{2} \varepsilon^{m_{2}} A_{3} \dot{\varepsilon}^{m_{3}}
$$

Table 1. Classifications of cracks: V-shape-open, Y-shape-half open or l-shape-closed. Cracks are located in the grooves side $(G)$ or grooves free side $(S)$ in the experiment.

\begin{tabular}{|c|c|c|c|c|c|c|}
\hline $\begin{array}{c}\text { Groove no: } \\
\text { Shape }\end{array}$ & $\begin{array}{c}1 \\
\text { Oval }\end{array}$ & $\begin{array}{c}2 \\
\text { False round }\end{array}$ & $\begin{array}{c}3 \\
\text { Oval }\end{array}$ & $\begin{array}{c}4 \\
\text { False round }\end{array}$ & $\begin{array}{c}5 \\
\text { Oval }\end{array}$ & $\begin{array}{c}6 \\
\text { False round }\end{array}$ \\
\hline$\{1\}$ & Y-G & I-S & I-G & I-S & V-S & V-G \\
$\{2\}$ & V-G & I-G & V-S & Y-G & I-G & I-G \\
$\{3\}$ & V-S & V-G & V-G & & Y-S & \\
\hline
\end{tabular}

Table 2. Comparison of relative crack depths from experiments and from FEM simulations without and with cracks. Shape of the cracks after rolling. Y-shape means half open and I-shape means closed crack.

\begin{tabular}{|c|c|c|c|c|c|c|}
\hline \multirow{2}{*}{ Pass } & \multirow{2}{*}{ Position } & \multicolumn{2}{|c|}{ FEM simulations } & \multicolumn{2}{|c|}{ Experiment } \\
& & $c_{i}^{\text {rel }}$ & $c_{i}^{\text {rel }}$ & shape & \multirow{2}{*}{$c_{i}^{\text {rel }}$} & shape \\
& & 0.77 & 0.94 & $\mathrm{I}$ & 0.62 & $\mathrm{Y}$ \\
& Bottom & 0.85 & 0.79 & $\mathrm{I}$ & 0.26 & $\mathrm{~V}$ \\
1 & $45^{\circ}$ & 1.01 & 1.18 & $\mathrm{Y}$ & 0.61 & $\mathrm{~V}$ \\
\hline \multirow{3}{*}{2} & Opening & 0.91 & 1.13 & $\mathrm{I}$ & 0.80 & $\mathrm{I}$ \\
& Opening & 1.08 & 1.02 & $\mathrm{I}$ & 0.46 & $\mathrm{I}$ \\
& $45^{\circ}$ & 0.99 & 1.15 & $\mathrm{I}$ & 0.42 & $\mathrm{~V}$ \\
\hline
\end{tabular}

With the material parameters:

$$
\begin{array}{ll}
\sigma_{0}=247.7 \mathrm{MPa} & \\
A_{1}=13.235 & m_{1}=0.00258 \\
A_{2}=1.23 & m_{2}=0.091 \\
A_{3}=0.76 & m_{3}=0.119
\end{array}
$$

Calculations were made on solid bars without cracks for the node at the same distance from the bar surface as the crack bottom in the rolling experiments. The bottom and face nodes were transferred in the tangential direction. In cluded in the model

\section{Results and Discussion}

Table 1 shows the shape of the cracks and the position of the cracks at the exit plane. There is correlation between the changes in depth and opening or closing of the cracks. The "relative crack depth" is shown in Figure $\mathbf{4}$ for the experiments and the FEM simulations with and without cracks.

cracks at the bottom of the round grooves were reduced. athe groove bottom and on the side in the alternack $\{2\}$ will always be in a position to make contact with the groove at least at the exit of the deforma-

Figure 4a shows the results for crack $\{1\}$. The experiments and the FEM calculations show the same tendency except for the last oval. The reason for this deviation is instability when rolling a fairly "round" false round bar. The experiment was carried out at a fairly high reduction, and the width of the false round section was larger than the "diwer" due to the high degree of groove filling. By twistin the succeeding groove, the false round section was comes lowest. Due to this situation the crack positions deviated in the experiments from the expected positions. The crack depth in the experiment is the distance from the crack

Figure $4 \mathrm{~b}$ shows the result for crack $\{2\}$ in $45^{\circ}$ position. In the first oval both experiments and calculations shows that the relative crack depth has decreased. In the following passes the relative crack depth has increased. Both crack $\{1\}$ and $\{2\}$ decreased in the oval grooves and increased in the false round grooves according to the calculations. In the experiments, the false round rolled in the second oval shows a different behaviour. Table 1 show that the crack is located at the groove opening which is another indication of instability. This means that the position of that crack is in the wrong position in all the following passes, which also can be seen in table 1 .

Figure $\mathbf{4 c}$ shows the result from crack $\{3\}$. The position of the crack is on the free side of the ovals and in the groove bottom of the false 
rounds. In the experiment, the crack depth decreased rapidly but this was not the case in the FEM calculations. The reason for this is probably that the chosen element size is too coarse to represent the local strains in the neighbourhood of the rolls. This can also be seen on crack $\{1\}$ where the experimental change of the crack depths is more dramatically in all passes than the calculated ones. In the experiments, crack $\{3\}$ disappeared in pass four and six while a relatively deep crack was found after five passes. An explanation to these contradictory results might be that the crack, located in the contact with the groove in pass number three instead of the expected position at the groove opening, has been folded over and inclined to an I-shaped crack, that might have been interpreted as a layer of decarburisation rather than a real crack. Also in this case, instability of the extremely well filled false round sections is the reason for the nonconforming crack behaviour.

A comparison of the "relative crack depth" for FEM simulations with and without cracks and with the experimental results is shown in Table 2. The FEM simulation with cracks in the first oval pass shows that crack $\{1\}$ in the groove bottom is closed, and has a depth of $1.22 \mathrm{~mm}$ compared to the FEM simulation without cracks where the depth is $1.15 \mathrm{~mm}$. Crack $\{3\}$ on the free side, has opened to 0.76 $\mathrm{mm}$, and is $1.55 \mathrm{~mm}$ deep, compared to the simulation without crack which has a depth of $1.51 \mathrm{~mm}$. The nodes in the bottom of crack $\{1\}$ and $\{3\}$ are only moved in radial and longitudinal direction.

In the calculation for crack $\{2\}$ in $45^{\circ}$ direction, the crack is closed and the depth is decreased to $1.04 \mathrm{~mm}$ compared to $1.27 \mathrm{~mm}$ in the calculation without crack. The upper surface node is displaced forward in relation to the node at the free side. The node at the crack bottom moved tangentially positive or counters clockwise relative to the nodes at the surface.

In the oval pass all cracks have been closed. Crack $\{1\}$, which is placed on the free side in the second pass, has a depth of $1.63 \mathrm{~mm}$ compared to $1.22 \mathrm{~mm}$ for the FEM simulation without crack. Crack $\{3\}$, placed at the groove bottom, has only been closed and not changed in depth at all.

Crack $\{2\}$, in $45^{\circ}$ position, has increased to $1.76 \mathrm{~mm}$ compared to $1.45 \mathrm{~mm}$ for the calculation without crack.

The FEM calculations, with and without cracks for first two passes, show the same tendency. In the first sequence, crack $\{1\}$ and $\{2\}$ are reduced and closed, in the both FEM simulations, due to the high compression in
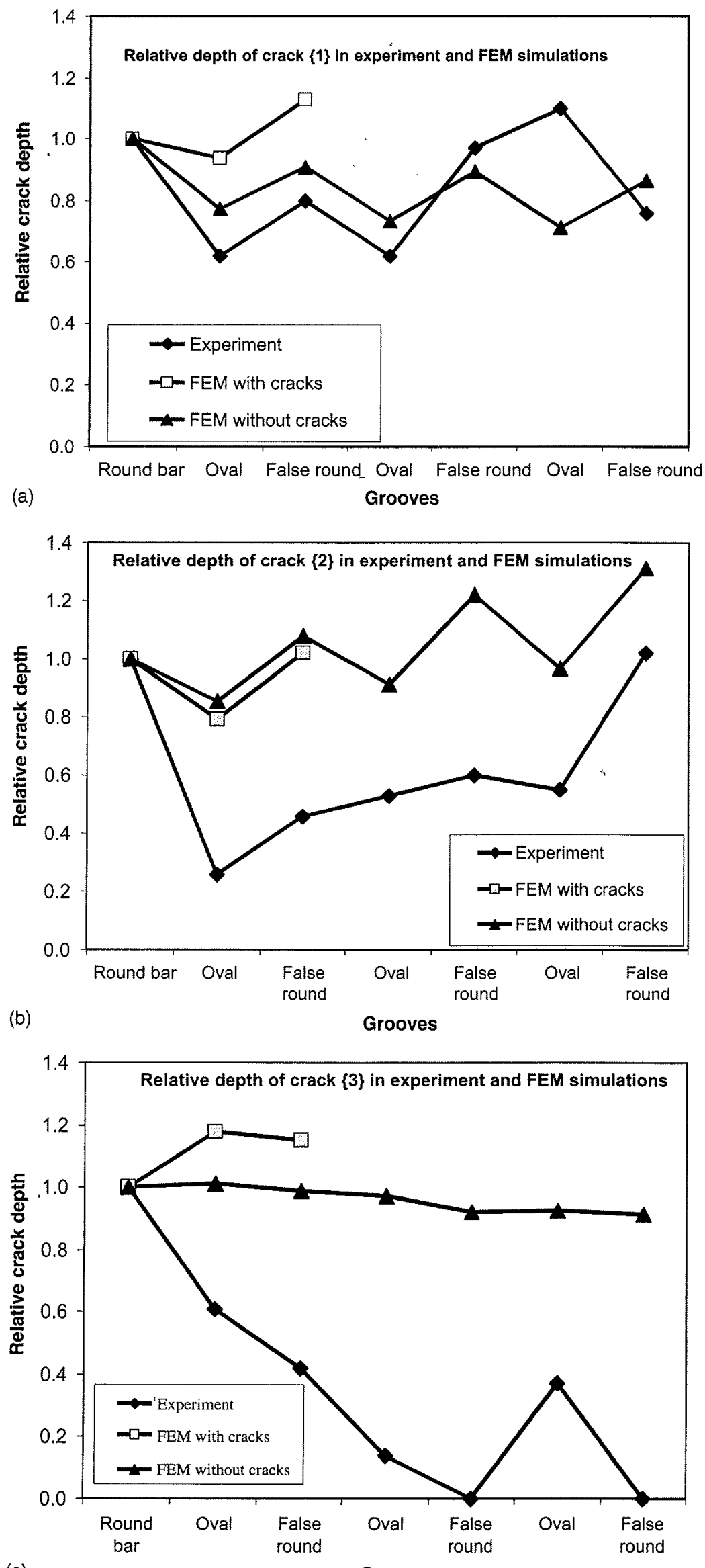

(c)

Grooves

Figure 4. Relative depths of the V-shaped cracks $\{1\},\{2\}$ and $\{3\}$. Comparison of experimental and FEM simulation without and with cracks; (a) crack $\{1\}$, (b) crack $\{2\}$ and $(c) \operatorname{crack}\{3\}$. 
grooves. This is also the case in the oval-false round sequence for crack $\{3\}$ at the groove bottom. But for the ovalfalse round sequence, crack $\{1\}$ and $\{2\}$ are increased due to low radial strain, but high longitudinal and tangential strain. The same is the case for crack $\{3\}$ in the false roundoval sequence.

The rapid closure of cracks, for the roll diameter of 320 $\mathrm{mm}$ and heavy reductions, is expected because these conditions gives a high hydrostatic pressure, which is favouring crack closure especially close to the groove bottom where workpiece is in close contact with the roll.

Generally, the experiments show faster reduction on the crack depth than the FEM calculations. The reason is probably that the contact algorithm is not perfect and a dramatically finer element mesh is necessary to model the local strains in the contact with the rolls. To eliminate closed cracks, which during rolling becomes deeper, is difficult. It may be possible to reduce the depth for high elongation, tensile strain in the angular direction and high compressive strain in the radial direction. This situation is obtained by high compression in radial and tensile strain in the longitudinal direction in the groove bottom in false round and ovals grooves, and also in all positions in the ovals. But for the false round grooves in the $45^{\circ}$ direction and on the free side, a substantial closing effect on the cracks with low compression in radial direction is obtained and the cracks will increase. The ovals are more efficient to reduce cracks. Thus, an efficient method to reduce cracks is to use substantial high reduction in the ovals and moderate reductions in the false rounds.

FE studies in combination with practical experiments are necessary in order to understand how the material flows in the groove and to explain whether the crack will open up to a V-shape or if it will be closed to an I-shape.

However a deeper study of the problem is necessary in order to fully understand the influence of rolling geometry on the elimination of cracks. One suggestion can be to choose a finer element size which can take care about the local strains in the neighbourhood of the rolls. However, simulation of the crack behaviour in several consecutive passes during the rolling process is very complicated and serious efforts are necessary in order to make a real step forward

\section{Conclusions}

- FEM simulations are good tools for analysis of cracks behaviour. However, experimental results always show faster reduction of the cracks than the FEM calculations.

- FEM simulations with cracks and without cracks show the same tendency, but a finer element size in the field of the crack will probably give better results compared to experiments.

- Cracks located in the groove bottom are always reduced in depth.

- High reduction often increases the rapid closure of a crack, especially in the groove bottom where the contact is closest.

- The changes in crack depth are connected to the opening or closing of the cracks in the groove.

- Defects, both in the $45^{\circ}$ directions and on the free sides, are closed when rolled in oval grooves, at the same time as their depths are reduced.

- Cracks at all positions are closed in oval-false round pass, but their depth is increased.

- For the false round groove, the material surfaces in the $45^{\circ}$ direction and on the free side will be compressed in the angular direction and elongated. The result is a closed crack with an I-shape.

- The FE calculations show higher tendency to close the cracks than demonstrated in the experiments.

- Oval grooves combined with high reduction are more efficient to reduce cracks depth in all positions on the surface.

- Cracks depth increases in $45^{\circ}$ direction and on the free side in false round grooves. In false round passes, a moderate reduction is recommended.

\section{Acknowledgements}

We wish to thank our friend Professor Sven-Erik Lundberg, Örebro University, for many discussions, good ideas, help and patience. Thanks are due to the Swedish Steel Producers' Association (Jernkontoret) research committee 3277. Special thanks to Ms Therése Gustafsson for all her help with the CAD-drawings connected to the pass design. Finally, our thanks go to Fagersta Stainless AB and Knowledge Foundation for support.

(SJM 5835; originally submitted to Scandinavian Journal of Metallurgy, received on 16 June 2005 , accepted on 28 June 2005)

Contact: Mirjana Filipović

National Post Gradual School in Metal Forming

Dalarna University

SE-781 88 Borlänge / Sweden.

Email:mfi@du.se

\section{References}

[1] Lestani M.: La Revue de Metallurgie - CIT, 94 (1997), No. 10, 12251236.

[2] Lundberg S.-E.: BHM, 147 (2002), No.11, 333-344.

[3] Walzdrahtfehler, Wire rod defects, Les defaults dans le fil-machine, Verlag Stahleisen GmbH, Düsseldorf, 1973.

[4] Brimacombe J. K., Sorimachi K.: Metallurgical Transactions B, 8B (1997), 489-505.

[5] Eriksson C.: Bases for Design of Flexible Roll Pass Sequences for Wire Rod Rolling, Metallurgy and New Materials Researches for Publication, 13 (2005), No. 1, 1-20.

[6] Lundberg S.-E.: Stahl und Eisen, 124 (2004), No. 12, 141-147.

[7] Wallner G.: Flexibility in the rolling of bar and wire rod, (in Swedish), Doctoral Thesis, Dep. of Metal Forming, Royal Institute of Technology, Stockholm, 1976.

[8] Nyström A.: Working range and stability in rolling in grooves, (in Swedish), Doctoral Thesis, Dep. of Metal Forming, Royal Institute of Technology, Stockholm, 1980.

[9] Matsui T., Ogata S., Fujita M., Hasunuma M.: Annals of the CIRP, 23 (1974), 57-58.

[10] Lim K.-H., Kim H.-S., Cho Y.-K.: SEAISI Quarterly, (2000) July, $42-49$.

[I1]Ervasti E., Ståhlberg U.: Jour. of Materials Processing Tech., 94 (1999), 141-150.

[12]Eriksson C.: Steel Research Int., 75 (2004), No. 12, 818-828.

[13] Hensel A., Spittel T.: Kraft- und Arbeitsbedarf bildsamer Formgebungsverfahren, VEB Deutscher Verlag für Grundstoffindustrie, Leipzig 1978. 